\title{
Researchers discuss NIH's nanotechnology initiative
}

In late June, the US National Institutes of Health (NIH; Bethesda, MD) hosted a meeting $^{\star}$ to discuss how NIH officials should allocate their part of a $\$ 495$ million nanotechnology research initiative included in the Clinton fiscal year 2001 budget request. The field is expected to contribute broadly to medicine, including cancer diagnostics and treatment research, and the new toolsoriented initiative reinforces enthusiasm for concerted efforts to develop new technologies for generating and interpreting data. However, there is concern among would-be nanotechnology researchers that many nanotechnology projects do not fit neatly into what NIH review panels typically have favored, namely "hypothesis-driven" research to the exclusion of what they say nanotechnology needs instead-that is, "design-," "technology-," and "discoverydriven" research.

Other federal agencies, notably the National Science Foundation, are fully onboard the nanotechnology bandwagon. For instance, Nanogen (San Diego, CA) has benefited from federal funding from the Department of Justice, DARPA (Defense Advanced Research Projects Agency), and the National Institute of Standards and Technology; the National Cancer Institute is currently testing Nanogen's DNA-on-achip approach to detect single nucleotide polymorphisms (SNPs) associated with responses to specific antitumor treatments in cancer patients.

However, academic researchers are pointedly skeptical about NIH's commitment to the new field. "NIH is historically unfriendly to tool development," said Harvard University chemistry professor George Whitesides. "The NIH infrastructure doesn't support this area of research. . and many don't think NIH is a serious player." He said that NIH should put together special peer review panels to deal with this subject and that "an administrative home be developed within NIH with grant authority."

Richard Klausner, director of the NCI, says some of the "skepticism" about the NIH commitment to fund nanotechnology and tool development is "well placed," explaining that it has often been a "real struggle" to shepherd proposals for tool development through the peer review system at NIH. "There is an absolute, essential need for tool development," says Klausner. "We need suitable technologies to do comprehensive analyses, and we need to understand nanoscale processes." Currently, treatments of cancer are "disconnected with molecular understanding of the disease, with very few excep- tions," he says. "Good may come. . from the development of devices. . .and approaches for detecting critical molecular-scale changes that define the nature of the disease and drive us to therapies."

\section{The NIH infrastructure doesn't support this area of research...and many don't think NIH is a serious player.}

Richard Zare, a chemist who has developed single-molecule spectroscopy at Stanford University (Stanford, CA) and is considered a leader in the field, says that, although nanotechnology represents a "very important new field," laying its foundations entails making a break with the pastsomething that is not easy for NIH or for many universities where science and technology programs typically are organized around departments for which turf protec- tion often has the upper hand. "If NIH continues to do business as usual, it runs the risk of losing a major opportunity," he says. This warning is not exaggerated; it's very real. We're talking of how to support research to make new tools."

But top NIH officials say that traditional review regimes are already being revamped to ensure that nanotechnology projects are funded. NIH Deputy Director for Extramural Research Wendy Baldwin says that some of these changes already are being put in place. "We've explicitly changed the review criteria so that it's not only hypothesis-driven but also design-driven," she says. Moreover, the entire peer review system at $\mathrm{NIH}$ is in the throes of a multi-year retooling effort, one that entails changes in staff, reviewer attitudes, and in the overall "culture." That kind of "social change takes a long time," she says.

Jeffrey L. Fox

Nanoscience and Nanotechnology: Shaping Biomedical Research, held June 25-26 at the NIH Natcher Conference Center, Bethesda, MD.

\section{British Biotech redefines itself}

In early July, British Biotech's (Oxford, UK) annual results were released and, to the relief of investors, the company had cut its annual

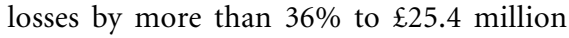
(\$38 million). For the past few years, the name of British Biotech has been synonymous with the oral anti-cancer drug, marimastat, a matrix metalloproteinase inhibitor (MMPI). The compound has been in largescale phase III trials for various cancers since 1996, but has never shown any substantial efficacy; British Biotech reported the fourth phase III failure (for glioblastoma) in June. Although the company is still optimistic about MMPIs, it has set about re-defining itself as an antibiotics company-a move most analysts think is wise.

British Biotech's share price has fallen

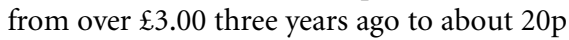
recently, and considerable restructuring over the past 2 years has reduced the workforce from 450 to 140 , leaving a much depleted research group of around 30 people.

Most analysts appear to have written off marimastat some time ago and, for Oliver

Sylvia Davidson is a freelance writer working in Brighton, UK.
Trefgarne, biotech analyst at Nomura (London), it is now "a tiny proportion of value." A major problem with its mode of action-acknowledged by British Biotechis that it does not kill cancer cells, but merely controls their growth and spread through the body. It is therefore not surprising that it has been unsuccessful against aggressive fast growing tumors. Results of two phase III trials in non-aggressive small cell lung cancer are due out later this year. These patients have low tumor burdens following earlier treatments, and if the results are negative, the product will finally be "terminated," according to Tony Weir, British Biotech's director of finance.

Steve McGarry, analyst at Goldman Sachs (London) notes, "while retail investors were fixated on marimastat, they did not notice that the company was building a nice early-stage pipeline behind [it]." This pipeline includes BB 3644, a follow-up to marimastat in phase $\mathrm{Ib}$ trials in cancer patients. BB 3644 does not appear to cause the musculoskeletal side-ffects that made long-term treatment with marimastat problematic. But, as Weir notes, the company will only "know by the end of the year whether it is a valid follow-on compound". 